\title{
Polish MAIN: how was it developed and how has it been used so far?
}

\author{
Karolina Mieszkowska \\ University of Warsaw
}

\section{Agnieszka Otwinowska}

University of Warsaw

\section{Marta Białecka-Pikul}

Jagiellonian University

\author{
Dorota Kiebzak-Mandera \\ Institute of Polish Language of Polish \\ Academy of Sciences
}

Marcin Opacki

University of Warsaw

\section{Ewa Haman}

University of Warsaw

This paper describes in detail the development of the Polish version of the Multilingual Assessment Instrument for Narratives (LITMUS-MAIN). We first describe its two earlier versions, the unpublished version and the published version, developed in 2012, as well as the revised version. We also justify the differences between the unpublished Polish version developed in 2012 and the original MAIN. Then we summarize the results from studies that used the unpublished version of the Polish MAIN. We end with outlining a study that could be conducted to compare the two slightly different procedures in order to examine whether the results obtained with MAIN are resistant to changes in the procedure details.

\section{$1 \quad$ Introduction}

This paper briefly introduces the development of the Polish version of the Multilingual Assessment Instrument for Narratives (LITMUS-MAIN, henceforth MAIN; Gagarina et al., 2012, 2019), focusing on the versions developed and the research conducted with the Polish MAIN (henceforth MAIN-Polish) so far. Before we proceed to a detailed description of the adaptation of MAIN to Polish, let us clarify that below we present information on two slightly different MAIN versions available for Polish: the unpublished MAIN-Polish and the published MAIN-Polish. The unpublished version of MAIN-Polish was developed in parallel to the original English-language MAIN (Gagarina et al., 2012) within the COST Action IS0804 Working Group "Narrative and 
Discourse" led by Natalia Gagarina and Joel Walters. However, before the original Englishlanguage MAIN (Gagarina et al., 2012) was published, the unpublished MAIN-Polish was already in use in Polish research projects. Despite the substantial similarity to the original MAIN (Gagarina et al., 2012), the unpublished MAIN-Polish differs from the original MAIN in several ways. The differences are described in detail in Section 3, and generally relate to the structure of the warmup, the way the story-pictures are presented to the child, the number of comprehension questions, and the order and the details of the elicitation modes (Telling, Model Story, and Retelling).

The published MAIN-Polish is a direct translation of the original English version of the MAIN (Gagarina et al., 2012). The published MAIN-Polish has been available since 2012, but has not been used in any studies on Polish monolingual or bilingual children, because the unpublished MAIN-Polish was already in use. The revised MAIN-Polish, published together with this paper, is based on the revised English version (Gagarina et al., 2019).

\section{The characteristics of Polish}

Before moving on to describing the development of MAIN-Polish, let us briefly present the Polish language whose characteristics influenced the Polish adaptation of the MAIN. Polish is a West Slavic language, spoken primarily in Poland as the official language (and one of the official languages of the European Union), but it is also used by Polish minorities in other countries. Altogether, there are nearly 40 million Polish-language speakers in Poland and about 20 million around the world, mostly due to migration (Tyciński \& Sawicki, 2009).

Polish is a highly fusional language with relatively free word order, although the dominant, word order is subject-verb-object (SVO), which is stylistically and pragmatically unmarked. Polish also has very rich inflectional and derivational morphology. This includes six cases - used to inflect all nouns, pronouns, and adjectives - two number classes (singular and plural), and grammatical gender (masculine, feminine, neuter). Additionally, masculine nouns (several of which are considered generic) include a further semantic mandatory subcategorization by personhood (+person, -person) and animacy (+animate, -animate) (Przepiórkowski et al., 2012) which are semantic properties of nouns rather than inflections, but still determine agreement in sentence structure. In Polish, there are no articles. Verbs are conjugated in a highly complex way (for grammatical personhood, gender, number, tense, mood, reflexivity, and aspect, Alberski et al. 2018) through a combination of grammatical and lexical features expressed via inflectional morphology (conjugation), derivational morphology (word formation), or a mixture of both. Thus, while verbs take on two basic aspects - the imperfective/progressive and the perfective - when the other conjugational properties are considered, each verb can take on a wide variety of forms. Since Polish is a pro-drop-language, subject pronouns are typically dropped (Nagórko, 1998; Sadowska, 2012). All these have important consequences in the case of the Polish adaptation of MAIN and its use for cross-linguistic comparisons and for comparisons of storytelling skills of bilingual children speaking Polish (as elaborated below). 
Before the original English-language version of MAIN (Gagarina et al., 2012) was published, the unpublished MAIN-Polish was already in use in the large-scale Polish research project Cognitive and language development of Polish bilingual children at the school entrance age - risks and opportunities (Bi-SLI-PL) led by Ewa Haman and Zofia Wodniecka, and in its successor Phonological and Morpho-syntactic Features of Language and Discourse of Polish Children Raised Bilingually in Migrant Communities in Great Britain (WLRB) led by Agnieszka Otwinowska. Thus, some of the published results related to bilingual children's narrative abilities were from the unpublished MAIN-Polish. The changes in the unpublished MAIN-Polish were made to ensure the procedure and the story scripts were as culturally appropriate as possible for Polish children aged 3-10. The adaptation procedure included translation of the story scripts by two translators, consultations with expert practitioners working with children, and the choice of language and style most suitable to what Polish children usually encounter in the context of storytelling. The data gathered with the unpublished MAIN-Polish allowed us to create a corpus of children's responses which also informed our coding and scoring procedures.

The published MAIN-Polish does not differ from the original English version of the MAIN (Gagarina et al., 2012). The published MAIN-Polish, however, has not been used in any studies on Polish monolingual or bilingual children because the early MAIN-Polish was already in use. In Table 1 below, we compare the detailed procedures of the original English MAIN (Gagarina et al. 2012) and the unpublished MAIN-Polish. The published MAIN-Polish is not included in the table, as it is identical with the original MAIN.

The differences between the original MAIN and the unpublished MAIN-Polish concern four aspects: the warm-up, the way of presenting the pictures to the child, the comprehension questions, and the order of the modes (Telling, Model Story, and Retelling). Each difference is discussed in detail below.

Warm up. In the unpublished MAIN-Polish, the warm-up was extended by adding more questions relevant to the context of story-telling. The questions directed the child's attention towards stories and fairy tales: "Do you know any stories or fairy tales?" If the child did not reply, the experimenter would provide some examples, such as: "It can be a fairy tale about Little Red Riding Hood or a true story about what happened yesterday to somebody at a shop". There were also additional questions about how true stories and fairy tales could begin and end. This was done to attune the child to the scheme of storytelling and to stimulate them to include the beginning and the ending in their own stories told afterwards. Also, as the last step of the warm-up phase, the child was encouraged to tell a short story if they wanted to. This served to both accustom the child to story-telling and to facilitate bonding between the child and the experimenter. This longer warmup phase was considered culture-specific and appropriate to the Polish context. Moreover, a longer warm-up was treated as a lead-in for the Telling mode (child telling a story by themselves) that followed. 
Karolina Mieszkowska et al.

Table 1. The differences between the original MAIN (Gagarina et al., 2012) and the unpublished MAIN-Polish. The published MAIN-Polish and the revised MAIN-Polish (2020) are identical to the original MAIN versions (Gagarina et al., 2012, 2019).

\begin{tabular}{|c|c|c|c|}
\hline & \multicolumn{2}{|c|}{ Original MAIN (Gagarina et al., 2012) } & Unpublished MAIN-Polish \\
\hline \multirow{4}{*}{ 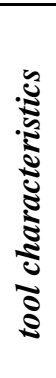 } & target group for the testing: & mono- and bilingual children aged 3-10 & [if empty, the procedure is the same as in the original MAIN] \\
\hline & evaluates & both comprehension and production of narrative & \\
\hline & elicitation modes: & Model Story, Telling, Retelling & same modes, but different order of the modes and procedures within the modes, see below \\
\hline & pictures: & $\begin{array}{l}\text { four parallel stories, each with a six-picture sequence: Baby Birds, } \\
\text { Baby Goats, Dog, Cat; } \\
\text { Procedures counterbalanced for research purposes. }\end{array}$ & \\
\hline & \multicolumn{3}{|l|}{ Instructions: } \\
\hline \multirow{4}{*}{ 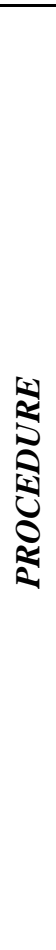 } & \multicolumn{2}{|c|}{$\begin{array}{l}\text { The warm-up phase: based on the experimenter's (EXP) previous experience and cultural } \\
\text { environment. While talking with the child, EXP is to establish rapport and ask some questions } \\
\text { to ensure that the child is able to understand simple wh-questions. Example of warm-up } \\
\text { questions included in MAIN manual: (1) Who is your best friend? (2) What do you like to } \\
\text { watch on TV? (3) Do you like telling stories? (4) Do you like listening to stories? }\end{array}$} & $\begin{array}{l}\text { Fixed protocol for the warm-up: after the original warm-up, additional questions are asked: } \\
\text { (1) Do you like listening to stories/fairy tales? (2) Do you like true stories? (3) Do you know } \\
\text { what a story/tale is? (4) Do you know any stories/tales? [If the child does not reply, EXP } \\
\text { provides examples: It can be a fairy tale about the 'Little Red Riding Hood"' or a story } \\
\text { about what happened yesterday to somebody at a shop.] (5) Do you know what a story/tale } \\
\text { always begins with? [If CHI does not answer, EXP: If it is a fairy tale, it can begin with } \\
\text { 'Once upon a time...' If it is a true story, it can begin with 'Once, when I was...' or } \\
\text { 'Yesterday, when I was doing the shopping...'] (6) And how does it always end? [If the child } \\
\text { does not reply or says I don't know, EXP: A fairy tale can end with 'And they lived happily } \\
\text { ever after', while a true story - with 'Then, I came back home and went to bed.' or 'This is } \\
\text { the end'] (7) Can you tell me about something? It can be a fairy tale or a true story. [If the } \\
\text { child talks too long (over } 3 \text { minutes) stop him/her gently and pass on to the procedure.] }\end{array}$ \\
\hline & \multicolumn{2}{|c|}{$\begin{array}{l}\text { D. Make sure that the three envelopes containing the same picture sequence are on the table } \\
\text { before assessment begins. (The purpose of this presentation format is for the child to think that } \\
\text { the examiner does not know which story is in the envelope s/he has chosen, thus controlling for } \\
\text { the effect of shared knowledge during the presentation of the picture sequences.) }\end{array}$} & \\
\hline & \multicolumn{2}{|c|}{$\begin{array}{l}\text { E. Administer the assessment according to the instructions in the story protocol(s). Please } \\
\text { adhere to the recommendations for prompts. }\end{array}$} & \\
\hline & \multicolumn{2}{|c|}{$\begin{array}{l}\text { F. Additional information about the presentation of the pictures: During the experiment you } \\
\text { should sit opposite the child so that the child can hold the pictures facing towards him/her, but } \\
\text { away from you. When the child takes the pictures out, tell him/her to unfold the pictures and to }\end{array}$} & $\begin{array}{l}\text { The procedure for the Telling mode is similar (EXP sitting opposite the child, non-shared } \\
\text { attention context). The procedure for Retelling is different: the EXP sits next to the child (so } \\
\text { that they can both see the story, shared-attention context), tells the story according to the }\end{array}$ \\
\hline
\end{tabular}


Polish MAIN: how was it developed and how has it been used so far?

look at the whole story starting from the first picture and say: "Look at the pictures but don't show them to me. Only YOU must see the story." (If the child cannot hold and unfold the

pictures him/herself, you may hold the pictures instead, facing away from you and towards the child.)

G. When the child is ready to tell the story, help him/her to fold the pictures into 3 parts again. You can direct the folding process without looking at the pictures while the child is still

holding them. Instruct the child to start telling the story whilst looking at the first two pictures.

When he/she has finished looking at pictures 1 and 2, direct the unfolding of the next two

pictures (pictures 1-4 will be unfolded now). When the child has finished, direct the unfolding

of the next two pictures so that the whole story is now unfolded. When the child has finished

telling/retelling the story, introduce the comprehension questions by saying "Now I am going

to ask you some questions about the story".

\section{The order of the modes within the testing:}

(1) Model Story (Cat/Dog): EXP and child sit opposite each other; EXP tells the child a story; followed by comprehension questions

model story and then asks the child to tell the same story again: Now, I'd like you to tell me the story again, as well as you can. Also, in all modes, all the pictures are unfolded at once.

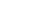

(2) Retelling (same story as in (1): Cat/Dog) EXP says: Now I want you to tell the story. Look at the pictures and try to tell the best story you can.

(3) Telling (Baby Birds/ Baby Goats): EXP and child sit opposite each other, child asked to look at the pictures and tell the story. EXP does not interfere, prompts allowed only if the child stops in the middle of the story.

No gradual unfolding of the pictures: in all the modes, the child sees (unfolds) all the picture at once.

Comprehension questions: (0) Did you like the story? (warm-up, not evaluated), (1) Why does the mother bird fly away? (2) How do the baby birds feel? (if no explanation is given then ask (3)) (3) Why do you think that the baby birds are feeling bad/ hungry etc.? (4) Why is the cat climbing the tree? (5) How does the cat feel? (6) Why do you think that the cat is feeling bad/ hungry/ scared etc.? (7) Why does the dog grab the cat's tail? (8) Imagine that the dog sees the birds. How does the dog feel? (9) Why do you think that the dog feels good/ fine/ happy/

satisfied etc.? (10) Who does the mother bird like best, the cat or the dog? Why?

(1) Telling (Baby Birds/ Baby Goats): EXP and child sit opposite each other, child asked to look at the pictures and tell the story. EXP does not interfere, prompts allowed only if the child stops in the middle of the story.

(2) Model Story (Cat/Dog): EXP and child sit next to each other; EXP tells the child a story.

(3) Retelling (same story as in (2): Cat/Dog) EXP says: Now I want you to tell the story. Look at the pictures and try to tell the best story you can; followed by comprehension questions.

Question (10) not asked; in Cat and Dog stories, question (2) focuses on picture 3 (where Cat/Dog has fell into the bush/banged its head in the tree), while in the unpublished MAINPolish, question (2) focuses on picture 1 (where Cat/Dog has just spotted the butterfly/mouse). 
Picture presentation. In the original MAIN (Gagarina et al., 2012), the picture stories were presented in three parts. The child was shown three separate episodes, two pictures per episode. The experimenter supervised the way in which the pictures were unfolded while the child was telling the story. First, the child would be asked to start telling the story while looking at the first two pictures. Then, once he/she has finished looking at pictures 1 and 2 , the experimenter would help unfold the next two pictures and then the following two, so that the whole story would be visible (unfolded) in the end. In our unpublished MAIN-Polish, the experimenter did not direct the unfolding of the pictures and the child could always see all the pictures at once (unfolded). Therefore, during the whole of the story telling in MAIN, the child sees all the pictures beforehand. This was based on the assumption that if the child saw the whole story upfront, it would be easier and more natural for them to follow the plot of the story. It was also considered more typical to the Polish scheme of story-telling.

Order of the modes and the setting of testing. Another difference in the unpublished MAIN-Polish, relative to the original MAIN (Gagarina et al. 2012), was the order of the modes and the setting of the testing. In Gagarina et al. (2012), the modes followed the order: Model Story (given by the experimenter, followed by comprehension questions), Retelling (the child retells the same story told by the experimenter), and Telling (the child is asked to tell a new story, based on another set of pictures, completely by themselves). In each of those modes, the experimenter and the child would sit opposite each other.

Importantly, however, the authors of the original MAIN (Gagarina et al., 2012) gave researchers flexibility in the choice of the modes for the testing and the order of the modes, stating that the choice of elicitation procedure depends on the goals and needs of the given assessment. Also, they stressed that the stories are essentially comparable (Gagarina et al., 2012). Therefore, in the unpublished MAIN-Polish, we opted for the order that would allow for the comparison of children's stories told spontaneously (based on picture-stories and without modeling) as well as those told after a model story was given by the experimenter. The order was the following: Telling (the child was asked to tell a story completely by herself/himself; the experimenter and the child sat opposite each other, and only the child saw the pictures to ensure a non-shared attention context), Model Story (the experimenter told a new story while sitting next to the child, i.e. in a shared-attention context), Retelling (the child retold the experimenter's Model Story, with both the experimenter and the child still seated next to each other). Thus, the unpublished MAIN-Polish contained two modifications when compared to Gagarina et al. (2012): first, the order of the modes in the Polish version is different. Second, in the Model Story and the Retelling modes, the experimenter and the child would sit next to each other and look at the picture story together, thus engaging in a shared-attention context. This modification was employed because shared story-reading is a more natural setting for storytelling, so it is more commonly found in the child's environment (Adrian et al., 2005; Bokus, 1978; Dyer et al., 2000). Moreover, the experimenter's behaviour during the Retelling, (i.e. viewing the pictures with the child and providing a coherent and linguistically rich model story) was used to potentially enhance the child's storytelling on the macro- and microstructure level. 
Comprehension questions. The last two differences between the unpublished Polish version and the original MAIN (Gagarina et al. 2012) relate to the comprehension questions and the pictures pointed to while one of the questions was asked. First, the unpublished MAINPolish did not include the last comprehension question in the Baby Birds/Baby Goats stories, i.e. "Who does the mother bird like best, the cat or the dog? Why?". This question was added to the original MAIN later, after MAIN-Polish was already being used for testing children. Second, in the original MAIN (Gagarina et al., 2012), the second comprehension question in the Cat and Dog stories refers to the story character's feeling in the third picture. The character in question (the dog/cat) in the third picture has just hurt himself by banging its head on the tree/falling into the bush, therefore the expected answer is that the $\mathrm{dog} / \mathrm{cat}$ is sad/unhappy/angry, etc. However, in the unpublished MAIN-Polish, this question points to the character (dog/cat) in the first picture, where the dog/cat has just spotted the mouse/butterfly and plans to catch it. In fact, the question in the unpublished MAIN-Polish retains its initial shape from the original MAIN, which was later on changed (after the unpublished Polish version was implemented in the Bi-SLI-PL study).

Some of the differences in the task procedures relative to the original MAIN (Gagarina et al. 2012) served to answer our particular research goals. For example, establishing an order of the testing modes constant across participants (first the Telling, then the Model Story followed by the Retelling) allowed us to compare the children's stories as told spontaneously (based on picture-stories) and as retold after a model story. Below, we present the results obtained with the use of the unpublished MAIN-Polish and presented in four publications (Haman et al., 2017; Mieszkowska, 2018; Otwinowska et al., 2018; Otwinowska et al., 2020). We then discuss them in relation to some studies that employed the original MAIN procedure.

The revised MAIN-Polish version (2020) is based on the revised English MAIN (Gagarina et al., 2019). It follows the MAIN procedure, but is amplified by the examples and outcomes gathered with the unpublished MAIN-Polish. Specifically, it contains examples of internal state terms found in children's stories (Mieszkowska, 2018, see below), and it reflects the characteristics of Polish. For example, in Polish, the goal is typically expressed by only using a preposition "żeby" (to) not coupled with a verb, i.e. compare English: "[The cat] leaped forward because he wanted to catch [the butterfly]"; Polish: "Kot dał susa żeby złapać mysz" ('The cat jumped to catch the fish'). Thus, the Polish version of the story scripts are adapted to the grammar and style typically used in story-telling.

\section{Results from the unpublished Polish MAIN}

Below we discuss the results obtained with the unpublished Polish MAIN. All the data for these analyses were gathered and maintained within two research projects: Bi-SLI-PL and WLRB. Altogether, over 160 Polish-English bilinguals (age range: 4.5-7 years, mean age: 5.5) were tested with MAIN (both the Polish and the English version). There were also over 260 Polish monolinguals (age range: 4-7, mean age: 5.5) and 25 English monolinguals (range: 4.5-8, mean age: 6) tested with the Polish and English MAIN versions. The analyses summarized below are 
based on subsamples from the same study. The number of participants differs across analyses as the largest possible subsample was used for each analysis, considering other variables for which data were available.

\subsection{Bilinguals and monolinguals do not differ in story macrostructure}

Previous studies have shown that similar age-dependent narrative patterns are shared by monolingual children from different language backgrounds (Berman \& Slobin, 1994). Based on our results, it also seems that narrative abilities develop similarly in bilingual and monolingual children, regardless of their language abilities. In one of the analyses (Haman et al., 2017), we compared Polish language performance across 53 Polish-English bilinguals and 53 Polish monolinguals matched on age, SES, and non-verbal IQ. The measures used for the comparison included productive and receptive vocabulary, productive and receptive grammar, phonological processing, as well as children's narrative abilities (the macrostructural coherence, i.e. story structure of their stories, as measured by the unpublished MAIN-Polish. Although the bilinguals lagged behind their monolingual peers in Polish on all language measures, on the narrative task they performed similarly to the monolinguals on the macrostructure measures. Specifically, their story structure scores were similar to those of monolinguals, replicating the results of Kunnari and colleagues (2016). The reason for this between-group similarity may be that producing coherent discourse taps not only into language abilities, but also into children's pragmatic awareness. Telling a coherent story involves not only vocabulary and the knowledge of grammar, but also cognitive skills which help to build a logical storyline (Gagarina et al., 2016; Paradis et al., 2014). This was also found to be the case in our analysis (Haman et al., 2017).

\subsection{The positive effects of story retelling on children's narrative performance}

In another analysis, we focused more on aspects of the discursive abilities of bilingual children as compared to their monolingual peers. We investigated whether the quality of the narrative (both in terms of the macrostructure and the microstructure) improves when the child is provided with a model story (Otwinowska et al., 2018). In our procedure of the unpublished MAIN-Polish the child was first asked to tell one of the picture-stories (Telling mode, nonshared attention context) and was then presented with the Model Story by the experimenter who next asked the child to retell the story (Retelling mode, shared attention context). The Telling was always performed before any model story was presented to the child. Thus, we were able to compare the stories told by bilinguals and monolinguals spontaneously (Telling mode) and following a model story (Retelling mode). We analyzed both the Polish and English language narratives obtained from 75 Polish-English bilinguals raised in the UK. We compared the Polish-language narratives with those produced by 75 Polish monolinguals matched with the bilinguals for gender, age, and non-verbal IQ (the children were also similar in terms of SES, but were not matched for it). We investigated whether retelling might improve bilingual and monolingual storytelling to the same extent. In the stories, we assessed both the macrostructure 
(e.g. story structure and answers to comprehension questions) and microstructure (e.g. type/token ratio, mean length of utterance, number of atypical patterns). We found a positive effect of retelling on macrostructure in both monolinguals and bilinguals. For bilinguals, their retold stories improved, as compared to the told stories, in both languages. As for the microstructure, when retelling, children told longer stories, regardless of the language (Polish, English) and group (bilingual, monolingual). The results from this study also showed that although the bilingual Polish stories contained a higher number of atypical patterns (syntactic and morphological errors) than the monolingual stories, the Mean Length of Utterance (MLU) remained significantly higher for the bilinguals, relative to the monolinguals, and regardless of the mode. These looked like conflicting findings, since errors usually indicate lower morphosyntactic skills, whereas a higher MLU is usually a marker of better syntactic abilities (Brown, 1973; de Villiers \& de Villiers, 1973). This led us to focus more deeply on the bilinguals' use of Polish and to analyze the results concerning children's MLU from a different perspective, as summarized below.

\subsection{Bilinguals overuse overt referential markers: MLU inflation in Polish-language narratives}

When telling a story elicited with MAIN, a child needs to maintain cohesion by using reference markers (e.g. nouns and pronouns) to refer to the story characters. When referring to new entities or story characters, children speaking such languages as English use indefinite determiners (predominantly articles) preceding nouns. For the known entities or characters, they use definite determiners. Also, when narrating in English, to mention a story character for the second time the child should use a pronominal form, such as an overt subject pronoun. However, in some languages referentiality can be expressed in other ways. As mentioned in Section 2, Polish lacks an article system and allows for null subjects. In Polish, referentiality is rendered mostly through morphological marking, while the use of determiners (e.g., demonstratives) and overt subject pronouns is allowed, but restricted for pragmatic reasons. Thus, thanks to complex morphosyntax and the lack of articles, Polish speakers may use fewer words than English speakers to express the same meaning and maintain referential cohesion within a story. This difference has an impact on how referentiality is realised in both languages. In (1) below we compare two sentences from the Baby Birds story scripts in Polish and English (Gagarina et al., 2012).

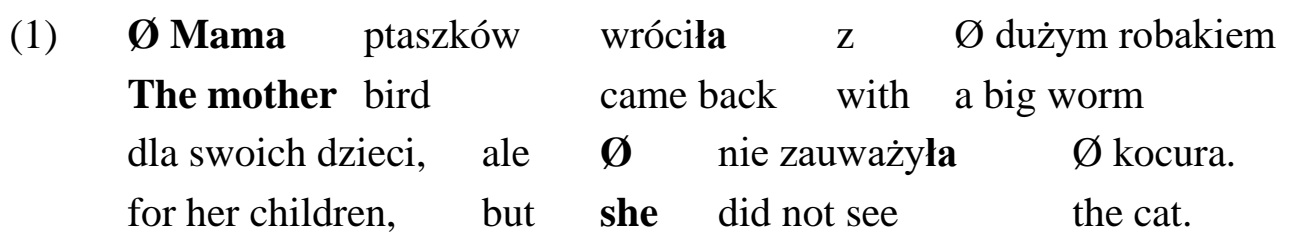

In (1), we see how referentiality in Polish is rendered through morphological marking, i.e. morpho-syntactic agreement between words when for the same referent, not through agreement for distinct referents. Items in bold represent the morphemes responsible for co-reference in the 
discourse track in both Polish and English. In Polish, the reference for the mother bird is maintained via the feminine morpheme which forces agreement in all verbs that are associated with the real-world referent. Note the empty slots $(\varnothing)$ where the English pronouns (carriers of reference) would be.

In our paper (Otwinowska et al., 2020) we investigated the use of referential markers in Polish narratives produced by Polish-English bilingual children and their Polish monolingual peers. We analysed data from 92 bilinguals and 92 Polish monolinguals matched for age, gender and non-verbal IQ (as before, the children did not differ in SES, but were not matched for it). For this analysis, to create a corpus of data, we merged the Telling and Retelling narratives of each participant. We were able to do so because there were no mode-differences in the data with respect to microstructure. A collapsing (i.e. merging of samples) of the data was carried out to increase the power of the analyses. The results corroborated the findings from the previous study (Otwinowska et al., 2018), whereby the bilinguals' MLU in Polish was significantly higher than that of the matched monolinguals. The reason for the increased MLU was that the bilinguals produced significantly more referential markers (especially personal and demonstrative pronouns), which inflated their word count. In other words, when producing narratives in Polish, the bilinguals overused referential markers, e.g. overt pronouns, as cohesive devices in their stories, which is not ungrammatical, but pragmatically odd in Polish. Such extensive use of referential markers was not found in the stories told by the matched Polish monolinguals. This finding can be explained as follows. Our bilinguals were immersed in English-language input, rich in overt pronouns within the noun phrases. As a result, they transferred the features of the English noun phrase to their Polish noun phrase, which led to increased use of demonstratives and personal pronouns as referential markers, which inflated the MLU. Thus, we conclude that the MLU inflation was caused by cross-language transfer at the syntax-pragmatics level.

\subsection{Internal state terms in the narratives}

The last analysis was part of a $\mathrm{PhD}$ thesis (Mieszkowska, 2018) that focused on internal state terms used in children's narratives. Internal state terms (ISTs) are words related to beliefs, desires, or emotions. Their examples include "think", "want", "notice", "surprised", "scared". ISTs are part of the MAIN procedure in at least three ways: they are present in the Model Story told to the child, they are assessed as part of the story episodes, and they are the focus of three out of ten comprehension questions. Mieszkowska investigated the use of ISTs in the children's narratives and performed a number of comparisons across a variety of conditions including: groups of children (bilingual vs. monolingual), bilingual children's languages (Polish vs. English), and modes of narrating (told stories vs. stories retold after the model). The analyses included data from 75 bilinguals and 75 monolinguals matched for age, SES, and non-verbal IQ. The children's stories were coded for three subclasses of ISTs: emotional, mental, and perceptual terms. Additionally, data on the children's vocabulary and grammar knowledge in their respective languages were included in the analyses, as were the results of their theory of mind performance tests, (Test of Reflection on Thinking, TRT; Białecka-Pikul et al., 2018). 
The results showed that while bilinguals exhibited poorer language abilities relative to monolinguals, the two groups did not differ in the amount of internal state terms produced when telling a story. However, the bilinguals outperformed their monolingual peers with respect to Theory of Mind as measured with TRT. Thus, the advantages and disadvantages seem to have cancelled each other out: the superior cognitive abilities of the bilinguals (as measured by TRT) and their weaker language abilities compared to the monolinguals (as measured by the vocabulary and grammar tests), led to no overall difference between the groups in the use of ISTs in the narratives. Also, the bilinguals used ISTs to a similar extent across their two languages (ISTs constituted approximately 3\% of all produced words in both languages). Finally, it was also found that providing children with a model story and explicitly asking them about the internal states of story protagonists attuned them to their knowledge, desires, and beliefs. This, in turn, resulted in using more ISTs in the retellings and answers to the comprehension questions than in the narratives told by children on the basis of pictures alone (Mieszkowska, 2018).

\section{Conclusions}

So far, there have been two previous versions of the Polish MAIN: the unpublished MAINPolish, used in a large scale study of Polish-English bilingual children living in the UK (the BiSLI-PL project), and the published MAIN-Polish, which is fully compatible with the original MAIN (Gagarina et al., 2012). The new revised version of MAIN-Polish (2020) strictly follows the changes introduced into MAIN by its designers (Gagarina et al., 2019).

The results obtained so far with the unpublished version of MAIN-Polish demonstrate that some aspects of narrative abilities (story macrostructure) show similarity across monolingual and bilingual groups, even if bilinguals lag behind monolinguals in other language skills like lexicon and grammar (Haman et al., 2017). Interestingly, the generally smaller vocabularies of bilinguals do not translate to a smaller amount of internal state terms in their speech compared to monolinguals (Mieszkowska, 2018). When telling a story after the experimenter, both monolinguals and bilinguals improve their stories' structures to the same extent (bilinguals showing this pattern in both of their languages) (Otwinowska et al., 2018). Nonetheless, these similarities between mono- and bilingual groups should not belie some intriguing differences: the stories of Polish-English bilinguals tend to have higher MLU than those of Polish monolinguals. A corpus analysis of narratives demonstrated that this is due to the overuse of referential markers in the narratives of bilinguals, which is in turn caused by cross-language transfer at the syntax-pragmatics level from English to Polish (Otwinowska et al., 2020).

It is important to stress that the differences in the unpublished MAIN-Polish were thus far never empirically contrasted with the published MAIN-Polish. To this end, a new study should be planned, with the aim of systematically comparing the two slightly different procedures on one group of participants (with a repeated-measures design). Such a study could reveal the extent to which the results of either micro- or macrostructure analysis depend on specific elements of the procedure, such as the introductory prompt meant to activate story- 
telling in participants or the exact order of picture presentation. Thus, it would show whether the results obtained with MAIN are resistant to changes in the procedure details. This is important, as many researchers adjust tools such as MAIN to cater to the needs of their particular studies/projects without fully reporting the minor differences in the procedure itself. Although the MAIN manual warns against introducing changes to the procedure, so far its potential sensitivity or resilience to procedural alterations has not been empirically tested. Nonetheless, when reporting the results of studies carried out with MAIN, researchers should make it a point to carefully and overtly acknowledge any deviations from the original procedure to avoid misunderstandings. Such changes compromise the feasibility of cross-study and crosslinguistic comparisons. Thus, the results obtained with the unpublished MAIN-Polish should be also treated with due caution when comparisons with other studies are made, since the procedure was not identical to the original one (Gagarina et al., 2012).

\section{Acknowledgments}

The unpublished MAIN-Polish was developed within the COST Action IS0804 Bi-SLI and for the purposes of the Bi-SLI-PL research project Cognitive and language development of Polish bilingual children at the school entrance age - risks and opportunities. The project was carried out at the Faculty of Psychology, University of Warsaw, Poland (PI: Ewa Haman) in collaboration with the Institute of Psychology, Jagiellonian University, Poland (co-PI: Zofia Wodniecka). The project was supported by the Polish Ministry of Science and Higher Education /National Science Centre (Decision 809/N-COST/2010/0). Data collection, data coding and maintenance were also supported by the Polish Ministry of Science and Higher Education grant (Decision 0094/NPRH3/H12/82/2014) Phonological and Morpho-syntactic Features of Language and Discourse of Polish Children Raised Bilingually in Migrant Communities in Great Britain, carried out at the Faculty of Modern Languages, University of Warsaw, Poland (PI: Agnieszka Otwinowska) and by the Foundation for Polish Science subsidy to Zofia Wodniecka (FOCUS program).

\section{$7 \quad$ References}

Adrian, J. E., Clemente, R. A., Villanueva, L., \& Rieffe, C. (2005). Parent-child picture-book reading, mothers' mental state language and children's theory of mind. Journal of Child Language, 32(3), 673.

Alberski, B., Andrejewicz, J., Andrejewicz, U., Andrzejczuk, A., Batko, P., Brodzińska, M., Bukowiecka, H., Drabik, L., Filipczak, J., Grzeszak, A., Hajnicz, E., Itoya, B., Kaczmarska, E., Kalużna-Gołąb, M., Kocyba, N., Kozłowska, M., Linsztet, B., Łodzińska, A., Maciejewska, M., ... Żurowski, S. (2018). Walenty (2018-06-29). http://zil.ipipan.waw.pl/Walenty.

Berman, R. A., \& Slobin, D. I. (1994). Relating Events in Narrative: A Crosslinguistic Developmental Study. Psychology Press. 
Białecka-Pikul, M., Szpak, M., Haman, E., \& Mieszkowska, K. (2018). Teoria umysłu i jej pomiar u dzieci w wieku 4-6 lat: Test Refleksji nad Myśleniem. Psychologia Rozwojowa, 23(1).

Bokus, B. (1978). Effect of adult-shared vs. Nonshared perception of a picture on its description by the three-yearold. Polish Psychological Bulletin, 9(4), 239-243.

Brown, R. (1973). A first language: The early stages. Harvard U. Press.

de Villiers, J. G., \& de Villiers, P. A. (1973). A cross-sectional study of the acquisition of grammatical morphemes in child speech. Journal of Psycholinguistic Research, 2(3), 267-278.

Dyer, J. R., Shatz, M., \& Wellman, H. M. (2000). Young children's storybooks as a source of mental state information. Cognitive Development, 15(1), 17-37.

Gagarina, N., Klop, D., Tsimpli, I. M., \& Walters, J. (2016). Narrative abilities in bilingual children. Applied Psycholinguistics, 37(1), 11-17.

Gagarina, N., Klop, D., Kunnari, S., Tantele, K., Välimaa, T., Bohnacker, U., \& Walters, J. (2019). MAIN: Multilingual Assessment Instrument for Narratives - Revised. ZAS Papers in Linguistics, 63.

Gagarina, N. V., Klop, D., Kunnari, S., Tantele, K., Välimaa, T., Balciuniene, I., Bohnacker, U., \& Walters, J. (2012). MAIN: Multilingual Assessment Instrument for Narratives. ZAS Papers in Linguistics, 56.

Haman, E., Wodniecka, Z., Marecka, M., Szewczyk, J., Białecka-Pikul, M., Otwinowska, A., Mieszkowska, K., Łuniewska, M., Kołak, J., Miękisz, A., Kacprzak, A., Banasik, N., \& Foryś-Nogala, M. (2017). How Does L1 and L2 Exposure Impact L1 Performance in Bilingual Children? Evidence from Polish-English Migrants to the United Kingdom. Frontiers in Psychology, 8. https://doi.org/10.3389/fpsyg.2017.01444

Kunnari, S., Välimaa, T., \& Laukkanen-Nevala, P. (2016). Macrostructure in the narratives of monolingual Finnish and bilingual Finnish-Swedish children. Applied Psycholinguistics, 37(1), 123-144.

Mieszkowska, K. (2018). Internal State Lexicon of bilingual and monolingual pre-and early school children [PhD dissertation, University of Warsaw]. https://depotuw.ceon.pl/handle/item/2878

Nagórko, A. (1998). Zarys gramatyki polskiej: Ze słowotwórstwem (Wyd. 3. rozszerz). Wydawnictwo Naukowe PWN.

Otwinowska, A., Mieszkowska, K., Białecka-Pikul, M., Opacki, M., \& Haman, E. (2018). Retelling a model story improves the narratives of Polish-English bilingual children. International Journal of Bilingual Education and Bilingualism, 1-25.

Otwinowska, A., Opacki, M., Mieszkowska, K., Białecka-Pikul, M., Wodniecka, Z., \& Haman, E. (2020). The Overuse of Referential Markers in Polish by Polish-English Bilingual Children: Data from MLU in Narratives. First Language. https://doi.org/10.1177/0142723720933769

Paradis, J., Genesee, F., \& Crago, M. B. (Eds.). (2014). Dual language development and disorders: A handbook on bilingualism and second language learning (2nd ed). Paul H. Brookes Pub. Co.

Przepiórkowski, A., Bańko, M., Górski, R. L., \& Lewandowska-Tomaszczyk, B. (Eds.). (2012). Narodowy korpus języka polskiego: Praca zbiorowa. Wydawnictwo Naukowe PWN.

Sadowska, I. (2012). Polish: A comprehensive grammar. Routledge.

Tyciński, W., \& Sawicki, K. (2009). Raport o sytuacji Polonii i Polaków za granica 2009. Polski Instytut Spraw Międzynarodowych. 